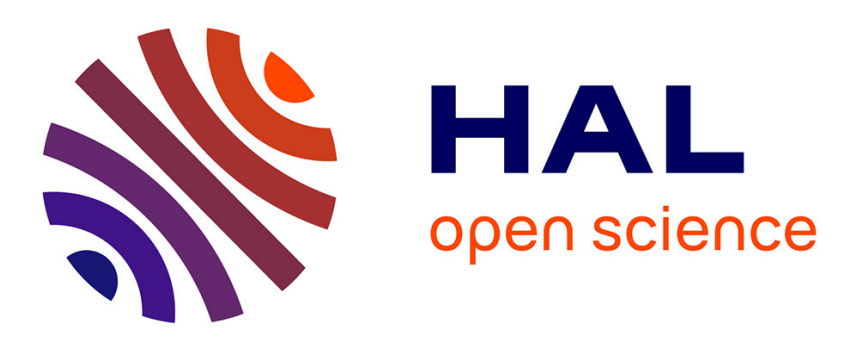

\title{
A Study of the Room Temperature Anelastic Creep of $\mathrm{Cu}-\mathrm{Be}$
}

\author{
S. Sgobba, M. Vögeli, H. Künzi, B. Ilschner
}

\section{To cite this version:}

S. Sgobba, M. Vögeli, H. Künzi, B. Ilschner. A Study of the Room Temperature Anelastic Creep of Cu-Be. Journal de Physique IV Proceedings, 1996, 06 (C8), pp.C8-251-C8-254. 10.1051/jp4:1996854 . jpa-00254662

\section{HAL Id: jpa-00254662 https://hal.science/jpa-00254662}

Submitted on 1 Jan 1996

HAL is a multi-disciplinary open access archive for the deposit and dissemination of scientific research documents, whether they are published or not. The documents may come from teaching and research institutions in France or abroad, or from public or private research centers.
L'archive ouverte pluridisciplinaire HAL, est destinée au dépôt et à la diffusion de documents scientifiques de niveau recherche, publiés ou non, émanant des établissements d'enseignement et de recherche français ou étrangers, des laboratoires publics ou privés. 


\title{
A Study of the Room Temperature Anelastic Creep of Cu-Be
}

\author{
S. Sgobba, M. Vögeli, H.U. Künzi and B. Ilschner \\ Laboratoire de Métallurgie Mécanique, Département des Matériaux, Ecole Polytechnique Fédérale de \\ Lausanne, 1015 Lausanne, Switzerland
}

\begin{abstract}
The future nanotechnology requires materials which are dimensionally and elastically stable within the nm-domain. Because of their elastic stability, $\mathrm{Cu}-\mathrm{Be}$ alloys are often used for the fabrication of elastic force sensors (spring elements). Anelastic and viscous creep limit the precision of such sensors. Therefore we have studied the anelastic and viscoelastic relaxations of $\mathrm{Cu}-\mathrm{Be}$ using laser heterodyne interferometery. This method allows to measure flexural displacements as small as $0.1 \mathrm{~nm}$. Our measurements revealed that the anelastic creep of $\mathrm{Cu}-\mathrm{Be}$ is influenced by the microstructure of the bulk sample as well as the surface condition. The observed influence of the surface on the anelastic creep suggests that the surface dislocation density controls the anelastic relaxation.
\end{abstract}

\section{INTRODUCTION}

$\mathrm{Cu}-2 \% \mathrm{Be}$ is a traditional alloy for the fabrication of springs. The high elastic limit, fatigue resistance, good workability, hardness, corrosion resistance and wide useful temperature range have made it the alloy of choice for a wide range of applications. After thermal treatment, it is elastically more stable than maraging steels, Al-Cu-fiber reinforced composites, and Al- $\mathrm{Zn}$ alloys and similar to Al-Cu alloys [1,2]. Laser heterodyne interferometry is a highly accurate technique allowing measurements of strains with a resolution of $10^{-10}$. Details of the experimental technique used for static measurements of relaxation, as well as the description of the geometry of the specimen, have been described in the work of Willemin et al. [3].

\section{ANELASTIC RELAXATION OF CU-BASED ALLOYS.}

There are but a few studies specifically devoted to the effect of alloying elements on the anelastic properties of $\mathrm{Cu}$. In the detailed work of Rotheram and Pearson [4], the relaxation mechanisms active in pure $\mathrm{Cu}$ and in some $\mathrm{Cu}$-alloys are investigated using internal friction measurements. In pure polycrystalline $\mathrm{Cu}$, an internal friction peak at a temperature of $673 \mathrm{~K}$ was observed, for a frequency of $1 \mathrm{~Hz}$. This peak is not present in single crystals and was therefore attributed to grain boundary relaxations. In addition, an important internal friction background was also observed. The activation energy of the grain boundary peak was $1.43 \mathrm{eV}$. Industrial $\mathrm{Cu}-\mathrm{Be}$ alloys normally contain small additions of $\mathrm{Co}$.

Mondino and Schoeck [5] observed that in a Cu-Co alloy an internal friction peak appeared only after prolonged aging and suggested that the peak was due to the misfit dislocations associated with the loss of coherency between the precipitates and the matrix. Furthermore, traces of $\mathrm{Fe}$ may also be present in industrial $\mathrm{Cu}-\mathrm{Be}$ alloys. Pelletier [6] observed an internal friction peak in a $\mathrm{Cu}-\mathrm{Fe}$ alloy $(2.1 \mathrm{w} \% \mathrm{Fe})$ which decreased continuously during aging. He attributed this peak to a Zener relaxation of coherent precipitates. At a measurement frequency of $1 \mathrm{~Hz}$ this peak is situated between 250 and $300^{\circ} \mathrm{C}$. At room temperature all these relaxations become much slower and may not be observable in a creep curve of limited duration. 


\section{EXPERIMENTAL}

We have measured the anelastic creep of the industrial alloy BERYLCO 25 produced by NGKBERYLCO. The nominal composition of the alloy is as follows: $\mathrm{Be}, 1.8 \%$ to $2 \%$; $\mathrm{Co}, 0.2 \% \mathrm{~min}$; $\mathrm{Co}+\mathrm{Ni}+\mathrm{Fe}, 0.6 \% \mathrm{max} ; \mathrm{Cu}+$ additions: $99.5 \% \mathrm{~min}$. In particular, the alloy has been measured in the quenched state, after a peak-aging $\left(338^{\circ} \mathrm{C}\right)$, an overaging $\left(360^{\circ} \mathrm{C}\right)$ and an underaging $\left(240^{\circ} \mathrm{C}\right)$ treatment. Aging was done either in air or in a protective atmosphere of $\mathrm{He}$ to avoid the penetrating oxidation typical of some $\mathrm{Cu}$ alloys. It is well known that the oxidation affects the mechanical properties of the alloy.

\section{EXPERIMENTAL RESULTS}

The results of the anelastic creep tests, as observed from the cantilever mode of flexural deformation, are presented in fig. 1 , for a measuring temperature of $22.4^{\circ} \mathrm{C}$ and a maximum stress of $94 \mathrm{MPa}$. Although the applied stress was less than one tenth of the yield stress of the hardened alloy, a small irreversible component of the total strain remained following the complete relaxation after the load cycle. The anelastic creep curves of fig. 1 reveal that peak-aging gives the smallest relaxation amplitude. Surprisingly, samples treated under He for different aging times showed similar results. Only the quenched state differed from the aged states showing a larger relaxation amplitude. Fig. 2 presents the loading curves for peak aged samples treated either in a protective atmosphere or in air. When treating an as quenched sample in a $\mathrm{He}$ atmosphere, the aging considerably reduces the anelastic relaxation (peakaged $\mathrm{He}$ ). However, when the same treatments are done in air the anelastic relaxation increases considerably. Sandblasting, applied in order to remove the oxide layer of the air-treated sample, further increased the relaxation strength. After aging in $\mathrm{He}$, the sample had an excellent elastic stability. Only 160 ppm of the elastic deformation are observed as anelastic strain after $500 \mathrm{~min}$. In conclusion the elastic stability of $\mathrm{Cu}-\mathrm{Be}$ under flexural stress is strongly reduced by oxidation and by sandblasting, but is improved by precipitation hardening in a He atmosphere. The effect of over and under aging appears to be small. A power law $A t^{n}$ with an exponent $n=0.3$, as a first approximation, represents the anelastic behavior for each of the samples studied. The factor A depends strongly on the surface condition and on the bulk microstructure.

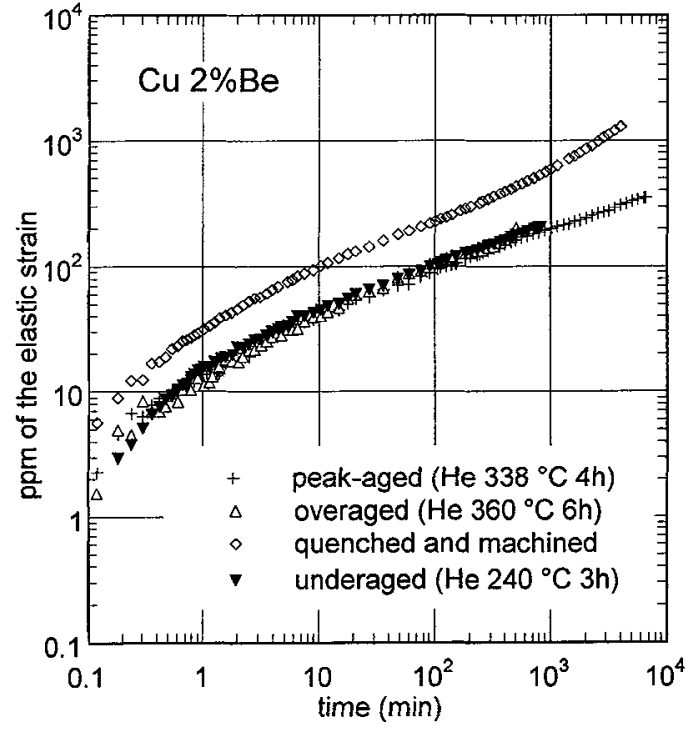

Fig. 1 Anelastic creep: effect of heat treating

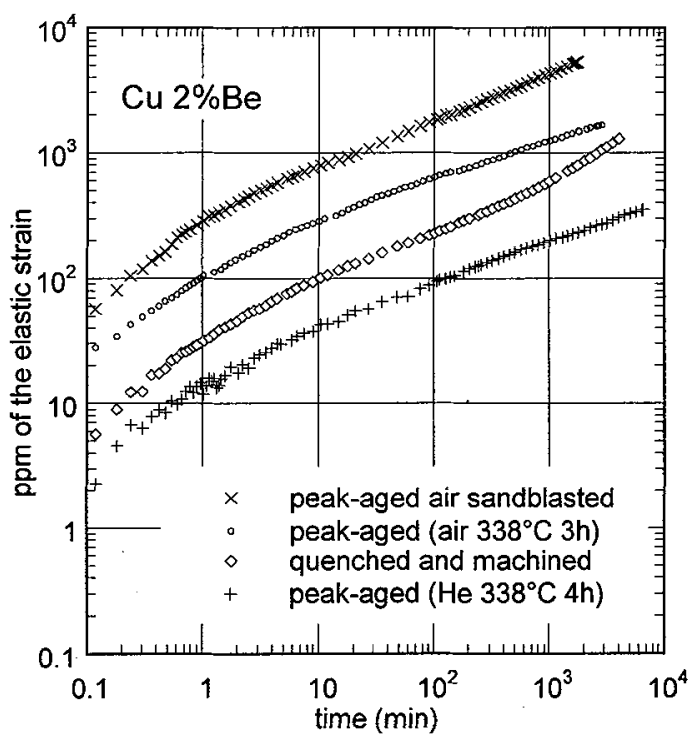

Fig. 2 Anelastic creep: effet of surface condition 


\section{SPECTRAL ANALYSIS OF THE RESULTS}

Dynamical measurements of the internal friction usually show more or less discrete Debye peaks superimposed on a continuous background. In static experiments we might therefore roughly expect an exponential relationship. However, none of the measurements displayed this simple behavior. In particular, even after prolonged measuring times, there are no signs of saturation. In order to obtain the dominant relaxation times our data should be subjected to spectral analysis. The problem to be solved consists in finding the function $G(\ln \tau)$ (the spectrum) which explains the observed anelastic creep curve according to

$$
\eta(t)=\int_{0}^{\infty} G(\ln (\tau)) \cdot\left(1-\exp \left(-\frac{t}{\tau}\right)\right) d \ln \tau
$$

Here $G(\ln \tau)$ can be either a continuous or a discrete spectrum. The numerical difficulties of finding the spectrum $G(\ln \tau)$ have been described elsewhere [7]. They substantially arise from the numerical instability of the inverse Laplace transformation [8]. Since there is no way to estimate the effect of this instability for a given set of data it is often better to use an approximate method which is less sensitive in this respect. Here we report on the results obtained by subjecting the experimental creep data of $\mathrm{Cu}-\mathrm{Be}$ to the approximate method of spectral decomposition as proposed by Schwarzl and Staverman [9]. In particular, we have used the second order approximation, which gives $G(\ln \tau)$ as

$$
\left.G(\ln \tau) \cong\left(\frac{d}{d(\ln t)}-\frac{d^{2}}{d(\ln t)^{2}}\right) \eta(t)\right|_{t=2 \tau}
$$

Fig. 3 shows the four spectra of relaxation times corresponding to the four curves of Fig. 2 . The asquenched state presents three pronounced peaks. These three peaks are still present for the sample aged under He, but this treatment clearly weakens their intensity. The peaks appear to be shifted when aging is done in air but are restored when the superficial oxide layer is removed by sandblasting (uppermost curve in fig. 3).

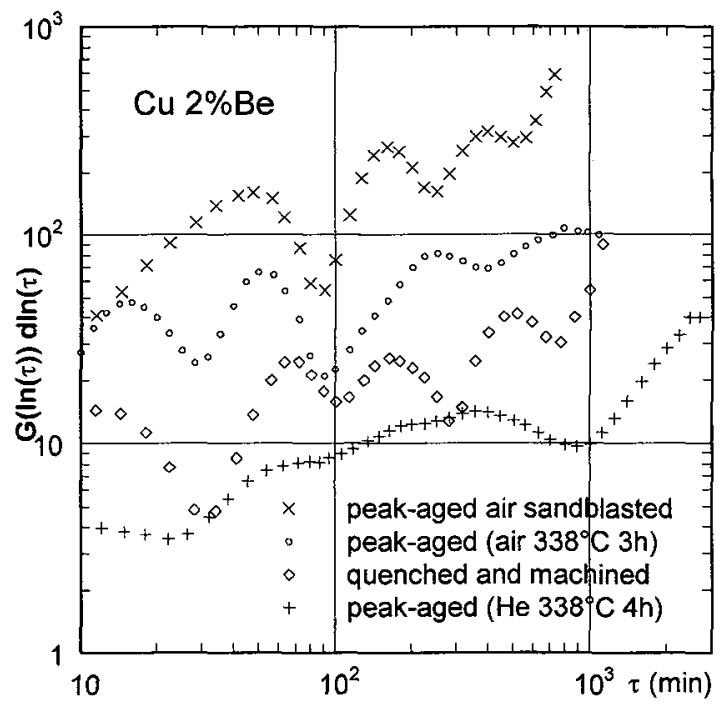

Fig. 3 Spectral densities obtained by the second order Schwarzl-Stavermann approximation

\section{DISCUSSION}

In previous work on $\mathrm{Al}-\mathrm{Cu}$ and $\mathrm{Al}-\mathrm{Zn}$ alloys $[1,2]$ we observed a strong reduction of the anelastic creep due to the presence of precipitates. The present study on $\mathrm{Cu}$-Be shows again that the same precipitates, which improve the mechanical properties of the alloy, are also contributing to its elastic stability. The experimental results on $\mathrm{Cu}-\mathrm{Be}$ furthermore show that the surface of our $1 \mathrm{~mm}$ thick sample strongly affects the elastic stability under flexural stress. Due to the poor oxidation resistance, $\mathrm{Cu}$ forms a 
significant layer of oxide very quickly even at moderately elevated temperatures. The new layer has in general weaker mechanical properties and will relax more strongly than the hardened base alloy. In a previous paper [1,7], we have discussed the strong influence of the surface layer on the anelastic behavior of Al-alloys. There we observed that a very thin layer (1/100 of the total thickness of the strip) with high relaxation damping can enhance the relaxation intensities by a factor as high as 100 .

The spectrum $G(\ln \tau)$ dln $\tau$ shown in fig. 3 increase when we do not take account of the oscillations roughly with the same slope of $n=0.3$ as do the creep curves (fig. 2). Even though we used only the second-order approximation of the Schwarzl-Staverman method this gives almost the exact result for a creep curve which follows the power law $t^{n}$. In fact, the Schwarzl-Staverman method becomes analytically correct only in the limit of the infinite order. Since the k-th order approximation involves a derivation of the experimental curve of order $\mathrm{k}$ results become practically insignificant for $\mathrm{k}>3$. Nevertheless, with respect to the power law, the method has the definite advantage of giving the correct exponent $\mathrm{n}$, independent of the order of the approximation. The constant of proportionality converges very rapidly. The oscillations or peaks that are superimposed on this mean slope are of course less certain. However, it is encouraging that they appear at the same positions $\tau$ for independent measurements. Their heights tend to follow the amplitude of the average anelastic creep. Aging of a quenched and machined sample in a He-atmosphere reduced considerably the peak heights. However, aging in air increased the anelastic strain, as well as the spectral density of the originally quenched and machined sample. The spectrum for this state differs from the others, but sandblasting returns the three peaks to their previous positions prior to aging in air.

Since both sandblasting and machining deform the surface layer plastically it appears that these peaks in the spectrum are due to dislocations. Annealing reduces the density of these dislocations. The effect is probably the same for heat treating in $\mathrm{He}$ as it is in air, but the penetrating oxidation and the oxide layer might introduce additional relaxation centers. Similar results have been observed in internal friction measurements on pure $\mathrm{Cu}$ by [4]. Heating in oxygen increases the internal friction at low temperatures $\left(0.200^{\circ} \mathrm{C}\right)$, while the grain boundary peak is reduced.

\section{CONCLUSIONS}

A comparison of creep curves of $\mathrm{Cu}-\mathrm{Be}$ measured after different thermal treatments shows that precipitation hardening increases the elastic stability of $\mathrm{Cu}-\mathrm{Be}$. With respect to the as quenched state (supersaturated solid solution), aging at temperatures between 240 and $360^{\circ} \mathrm{C}$ considerably reduced the anelastic relaxation. Contrary to findings in $\mathrm{Al}-\mathrm{Cu}$, under and over aging showed a smaller effect on the anelastic relaxation strength. The most important relaxation centers in $\mathrm{Cu}-\mathrm{Be}$ are recognized as the dislocations at the surface induced by surface treatments like sand-blasting and machining. The oxide layer also increased the relaxation level.

\section{Acknowlegements}

The authors are grateful to the Swiss National Science Foundation for financial support

\section{References}

[1] Sgobba S., Künzi H.U. and Ilschner B. Acta. Metall. Mater. 43 (1995) 1171-1181

[2] Sgobba S., Parrini L., Künzi H.U., Ilschner B. J. of Alloys and Compounds 211/212 (1994) 608-612

[3] Willemin J., Gietenbruch M., Gähwiler J. Schweizerische Gesellschaft für Mikrotechnik 14 (1990) 21

[4] Rotheram L., Pearson S. Trans AIME, Journal of Metals, Aug. (1956) 881

[5] Mondino M., Schoek G. Phys. Stat. Sol. 6 (1971) 665

[6] Pelletier J.M. Thèse NSA Lyon (1975)

[7] Sgobba S. Thèse EPF-Lausanne $N^{\circ} 1215$ (1994)

[8] Bellman R., Kalaba R.E., Lockhett J.A. 'Numerical Inversion of the Laplace Transform', Elsevier New York 1966

[9] Schwarzl F., Staverman A.J. Physica 18 (1952) 791-798 